\title{
Article \\ Adsorption Behavior and Dynamic Interactions of Anionic Acid Blue 25 on Agricultural Waste
}

Ensan Waatriah E. S. Shahrin ${ }^{1}$, Nur Alimatul Hakimah Narudin ${ }^{1}\left(\mathbb{D}\right.$, Nurulizzatul Ningsheh M. Shahri ${ }^{1}$, Sera Budi Verinda ${ }^{2}$, Muhammad Nur ${ }^{3}{ }^{\mathbb{D}}$, Jonathan Hobley ${ }^{4}$ and Anwar Usman ${ }^{1, * \mathbb{C}}$

1 Department of Chemistry, Faculty of Science, Universiti Brunei Darussalam, Jalan Tungku Link, Bandar Seri Begawan BE1410, Brunei; 20m8522@ubd.edu.bn (E.W.E.S.S.); 20m2042@ubd.edu.bn (N.A.H.N.); 20h8540@ubd.edu.bn (N.N.M.S.)

2 Biomedical Graduate Program, Faculty of Medicine, Universitas Diponegoro, Tembalang Campus, Semarang 50275, Indonesia; serabudiverinda@gmail.com

3 Center for Plasma Research, Integrated Laboratory, Universitas Diponegoro, Tembalang Campus, Semarang 50275, Indonesia; nur.cpr@gmail.com

4 Department of Biomedical Engineering, National Cheng Kung University, No. 1 University Road, Tainan City 701, Taiwan; jonathan.hobley@gmail.com

* Correspondence: anwar.usman@ubd.edu.bn

Citation: Shahrin, E.W.E.S.; Narudin, N.A.H.; Shahri, N.N.M.; Verinda, S.B.; Nur, M.; Hobley, J.; Usman, A. Adsorption Behavior and Dynamic Interactions of Anionic Acid Blue 25 on Agricultural Waste. Molecules 2022, 27, 1718. https://doi.org/ $10.3390 /$ molecules 27051718

Academic Editor: Marek Kosmulski

Received: 11 February 2022

Accepted: 1 March 2022

Published: 6 March 2022

Publisher's Note: MDPI stays neutral with regard to jurisdictional claims in published maps and institutional affiliations.

Copyright: (C) 2022 by the authors. Licensee MDPI, Basel, Switzerland. This article is an open access article distributed under the terms and conditions of the Creative Commons Attribution (CC BY) license (https:// creativecommons.org/licenses/by/ $4.0 /)$.

\begin{abstract}
In this study, adsorption characteristics of a negatively charged dye, Acid Blue 25 (AB25), on pomelo pith (PP) was studied by varying the adsorption parameters, with the aim of evaluating the adsorption mechanism and establishing the role of hydrogen bonding interactions of AB25 on agricultural wastes. The kinetics, intraparticle diffusion, mechanism, and thermodynamics of the AB25 adsorption were systematically evaluated and analyzed by pseudo-first-order and pseudosecond-order kinetic models, the Weber-Morris intraparticle and Boyd mass transfer models, the Langmuir, Freundlich, Dubinin-Radushkevich, and Temkin isotherm models, and the Van't Hoff equation. It was found that AB25 adsorption followed pseudo-second-order kinetics, governed by a two-step pore-volume intraparticle diffusion of external mass transfer of AB25 onto the PP surface. The adsorption process occurred spontaneously. The adsorption mechanism could be explained by the Langmuir isotherm model, and the maximum adsorption capacity was estimated to be $26.9 \mathrm{mg} \mathrm{g}^{-1}$, which is comparable to many reported adsorbents derived from agricultural wastes. Changes in the vibrational spectra of the adsorbent before and after dye adsorption suggested that AB25 molecules are bound to the PP surface via electrostatic and hydrogen bonding interactions. The results demonstrated that the use of pomelo pith, similar to other agricultural wastes, would provide a basis to design a simple energy-saving, sustainable, and cost-effective approach to remove negatively charged synthetic dyes from wastewater.
\end{abstract}

Keywords: acid blue 25; adsorption equilibrium; kinetics; mass transfer; adsorption mechanism; pomelo pith

\section{Introduction}

Soil and water environmental issues caused by the discharge of industrial wastewaters into water systems have become a global concern. In particular, the detrimental effects of the pollutants, such as heavy metals and synthetic dyes, on the entire ecosystem and human health have prompted the drive to develop effective approaches to remove the pollutants from wastewaters [1,2]. A variety of physical, chemical, and biological approaches, such as membrane filtration [3], flocculation [4], advanced oxidation [5,6], ozonation [7], adsorption [8-11], ion exchange [12], Fenton processes [13], and biodegradation [14] have been explored to remove heavy metal and dye effluents from wastewater. Among these promising methods to remove the pollutants, adsorption has attracted much attention because it is simple, cheap and practical to implement and can be handled even by a 
small-scale industry using non-toxic materials. Another key advantage is the wide variety of possible adsorbents that can be selected, ranging from naturally available materials to well-designed synthetic materials. Among them, agricultural wastes offer several benefits in terms of their cost effectiveness, their wide variety of functional groups, and their ability to scavenge heavy metal and synthetic dyes.

The cost of the adsorbents and their maximum adsorption capacity $\left(\mathrm{Q}_{\mathrm{m}}\right)$ are two of the important criteria used to evaluate their potential for cost-effective wastewater remediation. Industrial waste, agricultural waste, and biomass are among the most promising alternative materials used as adsorbents [10,11]. This is due to their low cost, reduced environmental footprint, and their availability. Moreover, agricultural wastes have plenty of functional groups which can readily chelate heavy metals or interact with organic dyes. In addition, they can be chemically modified to optimize the surface concentration of specific functional groups, and they can be carbonized followed by thermal or chemical activation to form activated carbon, which is the most effective adsorbent. By adapting and modifying the adsorption process, a variety of agricultural wastes have been explored as adsorbents [11,15-18].

One of the common toxic acidic dyes found in industrial wastewater, which could potentially contaminate ecosystems is Acid Blue 25 (AB25) [19]. In recent years, adsorptive removal of AB25 from aqueous solution has been investigated by exploring different types of adsorbents such as polymer-clay nanocomposites [20], pectin [21], activated carbons [22,23], and agricultural wastes. These include banana peel and durian peel [11], sawdust [15], Shorea dasyphylla sawdust [24], oak sawdust [15], cempedak durian peel [25], rambutan seed [26], hazelnut shells [15], shrimp shells [27], peach seed [28], plant leaves [29,30], and soybean waste [31]. Many of the adsorbents have been demonstrated to successfully remove AB25 from water systems with high efficiency. Despite this abundance of work, a detailed description of the adsorption characteristics of AB25, a negatively charged dye, remains a relatively uncharted area of research. Moreover, interactions between the dye and adsorbents, which are responsible for the adsorption of AB25 on agricultural wastes, have never been comprehensively discussed. Recently, it has been pointed out that low methoxy pectin isolated from pomelo pith (PP) shows the highest $Q_{m}$ of $A B 25$ due to the formation of hydrogen bonds with the galacturonic units of pectin strands which form gels in aqueous solution [21]. To further expand on the important role of hydrogen bonds, in the current study, the adsorption mechanism and hydrogen bonding interactions of AB25 on PP as a representative model of agricultural waste-based adsorbents are investigated. The objective of this work is therefore focused on assessing the adsorptive removal of AB25 on PP and its adsorption characteristics, including kinetics, isotherm, mechanism, rate-limiting step, and thermodynamics, and comparing these results with those for adsorption on pectin isolated from the pomelo pith and on other agricultural wastes. The adsorption behavior of AB25 was also investigated with respect to functional groups, pore size distribution, and other surface characteristics of PP. Intermolecular interactions between AB25 and PP were simulated using ab initio calculations using Gaussian basis sets.

\section{Results and Discussion}

\subsection{The Functional Groups and Surface Morphology of PP}

FTIR spectra of PP along with that of AB25 are shown in Figure 1. Before adsorption, PP showed vibrational bands at 3410, 2923, and $2852 \mathrm{~cm}^{-1}$ which are assigned to $\mathrm{OH}, \mathrm{NH}$, and $\mathrm{CH}$ vibrations. Those at 1748,1349 , and $1050 \mathrm{~cm}^{-1}$ are assigned to carbonyl $\mathrm{C}=\mathrm{O}, \mathrm{C}-\mathrm{C}$, and $\mathrm{C}-\mathrm{O}$ stretching vibrations, whereas the bands at 1632 and $1413 \mathrm{~cm}^{-1}$ are assigned to the asymmetric and symmetric stretching vibrations of carboxylic acid $(\mathrm{COOH})$ groups, respectively. These vibrational bands most likely originate from the functional groups of cellulose, hemicellulose, pectin, and lignin contained in PP [18,32,33]. Before adsorption, AB25 has bands at $\sim 1590$ and $1575 \mathrm{~cm}^{-1}$ (C=O stretch on anthrone), $1532 \mathrm{~cm}^{-1}$ (aromatic $\mathrm{C}=\mathrm{C}), 1500 \mathrm{~cm}^{-1}$ (aromatic $\left.\mathrm{C}=\mathrm{C}\right), 1415 \mathrm{~cm}^{-1}\left(\mathrm{~S}=\mathrm{O} \cdots \mathrm{Na}\right.$ stretch), $1280 \mathrm{~cm}^{-1}$ (C-N stretch on aromatic amine), $1230 \mathrm{~cm}^{-1}$ (C-N stretch), 1180, 1040, and $1020 \mathrm{~cm}^{-1}\left(\mathrm{SO}_{3} \mathrm{Na}\right)[11,34]$. 


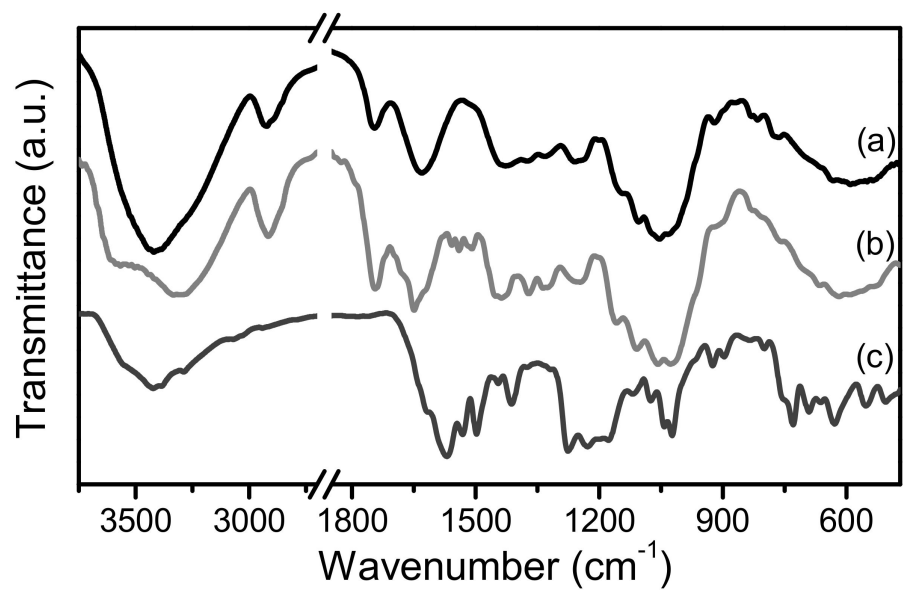

Figure 1. The FTIR spectra of (a) PP before AB25 adsorption, (b) PP after AB25 adsorption, and (c) AB25.

Upon AB25 adsorption, the FITR spectrum of PP in general showed similar features with those before AB25 adsorption with a few changes. In particular, there are changes in relative peak intensity of the vibrational modes of $\mathrm{C}-\mathrm{O}, \mathrm{C}=\mathrm{O}$, and $\mathrm{COOH}$ groups of PP. In the fingerprint region, both spectra show broad bands at 489-840, 930-1200, and $1211-1476 \mathrm{~cm}^{-1}$, and sharp intense bands at 1627,1653 , and $1744 \mathrm{~cm}^{-1}$. These spectral features could be broadly assigned to the superposition of the vibrational spectra of PP and adsorbed AB25, with expected spectral shifts due to intermolecular interactions between $\mathrm{PP}$ and $\mathrm{AB} 25$. It is interesting to note that the $\mathrm{OH}$ vibrational band of PP before adsorption $\left(3410 \mathrm{~cm}^{-1}\right.$ ) split into two bands at 3040 and $3568 \mathrm{~cm}^{-1}$ upon AB25 adsorption. This suggests that there are hydrogen bonding interactions between the $\mathrm{OH}$ groups of PP with functional groups of AB25 which play a key role in stabilizing adsorption of the dye on the adsorbent surface.

Figure 2 shows the SEM images of the PP before and after AB25 adsorption. These images suggest that the PP surface becomes smoother after adsorption. The BET surface area and total pore volume of PP were $12.3 \mathrm{~m}^{2} \mathrm{~g}^{-1}$ and $0.009 \mathrm{~cm}^{3} \mathrm{~g}^{-1}$, which is larger than those of other agricultural wastes such as banana peel and durian peel $\left(7.5 \mathrm{~m}^{2} \mathrm{~g}^{-1}\right.$ and $0.006 \mathrm{~cm}^{3} \mathrm{~g}^{-1}$, respectively) [11]. The surface area and total pore volume of PP after AB25 adsorption were reduced to $11.1 \mathrm{~m}^{2} \mathrm{~g}^{-1}$ and $0.006 \mathrm{~cm}^{3} \mathrm{~g}^{-1}$.
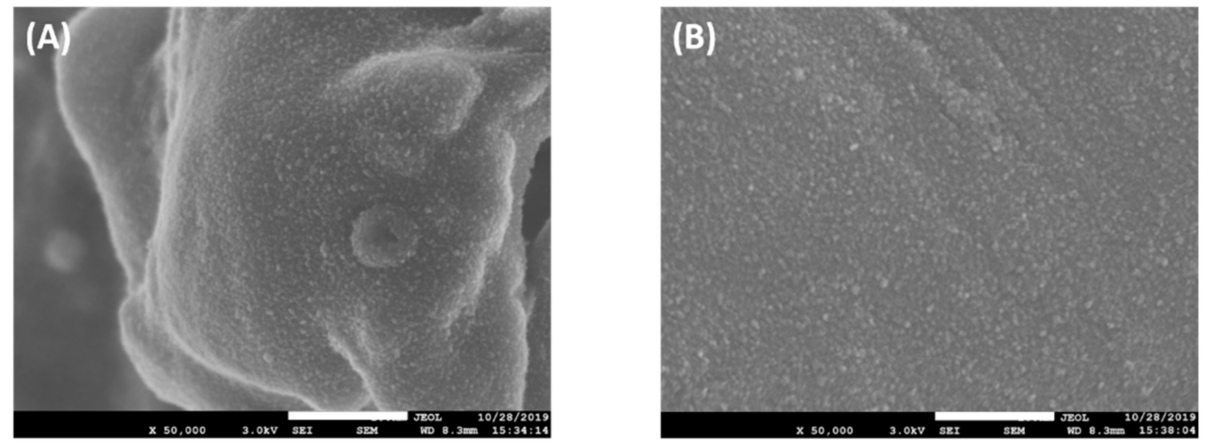

Figure 2. The SEM images of the PP surface (A) before and (B) after adsorption of AB25. All images were recorded at 50,000 $\times$ magnification, and the scale bars represent $500 \mathrm{~nm}$.

\subsection{Adsorption Characteristics of $A B 25$ on $P P$}

Adsorption of AB25 is manifest as a decrease in the absorbance of the remaining solution. Based on the absorption spectra of $20 \mathrm{~cm}^{3}$ solution of AB25 with an initial concentration, $\mathrm{C}_{0}=1.20 \times 10^{-4} \mathrm{~mol} \mathrm{dm}{ }^{-3}$, in the presence of $25 \mathrm{mg} \mathrm{PP}$, as shown in as shown in Figure $3 A$, the adsorptive efficiency $(\eta)$ and the adsorption removal capacity $\left(Q_{t}\right)$ 
as a function of contact time are calculated and presented in Figure 3B. It can be seen that the values of $\eta$ and $Q_{t}$ of AB25 adsorption on PP increased nonlinearly with the contact time, and an equilibrium state was achieved with a contact time of 120 min with $\eta$ and $Q_{t}$ being $43 \%$ and $9.32 \mathrm{mg} \mathrm{g}^{-1}$, respectively. It was also demonstrated that this equilibrium value increased nonlinearly with the adsorbent dosage (see Supplementary Information Figure S1). In this current study, PP showed a limited maximum removal efficiency of $85 \%$. In comparison, pectin derived from PP could completely remove AB25 from the aqueous solution under the same experimental conditions [21].
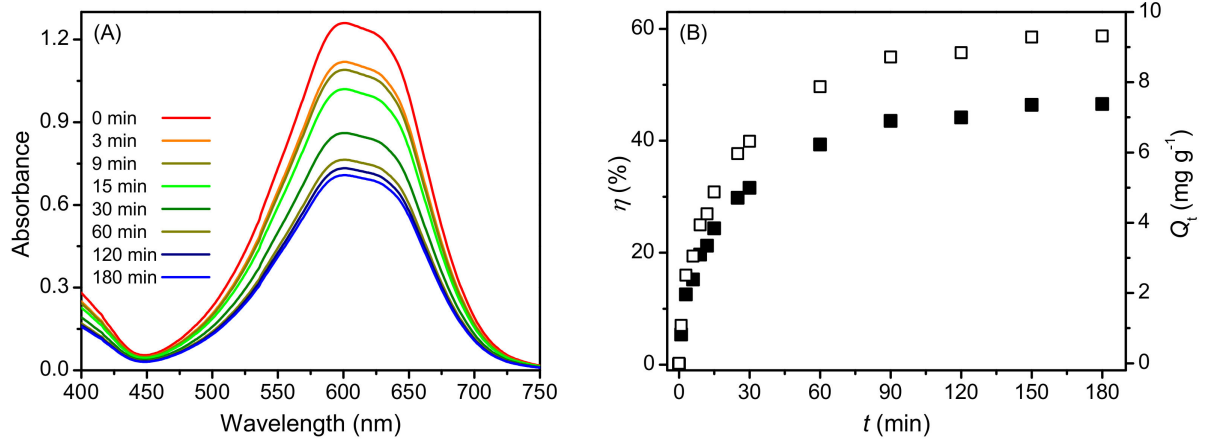

Figure 3. (A) Absorption spectra of AB25 on PP at different contact times, and (B) the adsorption efficiency $(\eta ; \mathbf{\square})$ and adsorption capacity $\left(Q_{t} ; \square\right)$ of AB25 as a function of contact time.

Simulations of Lagergren pseudo-first order and pseudo-second order on the adsorption kinetics of AB25 are shown in Figure 4A,B. Both kinetics models fitted well with the experimental data, but the regression coefficient $\left(\mathrm{R}^{2}\right)$ value of pseudo-second order $(0.998)$ is higher than that of pseudo-first order (0.980), suggesting that the former model is better to explain the adsorption kinetics of AB25 on PP. Based on the best fit of the pseudo-second order model, the adsorption capacity at the equilibrium state $\left(\mathrm{Q}_{\mathrm{e}}\right)$ was estimated to be $9.98 \mathrm{mg} \mathrm{g}^{-1}$, which is approximately reproduced the experimental results. The adsorption rate, $\mathrm{k}_{2}$, of AB25 on PP was $0.007 \mathrm{~g} \mathrm{mg}^{-1} \mathrm{~min}^{-1}$, suggesting low affinity of PP towards the acidic dye.

Simulation of the Weber-Morris intraparticle model on the adsorption kinetics data suggested a fast diffusion of dye onto the PP surface with a diffusion rate of $1.06 \mathrm{mg} \mathrm{g}^{-1} \mathrm{~min}^{-1 / 2}$ within the first $60 \mathrm{~min}$ of contact time. This was followed by a slower diffusion with a rate of $0.138 \mathrm{mg} \mathrm{g}^{-1} \mathrm{~min}^{-1 / 2}$ associated with achieving the equilibrium state. The zero $\mathrm{y}$-intercept of the best fit indicated that the thickness of the boundary layer was negligible (close to zero) and that the AB25 adsorption on PP was governed by a diffusion controlled rate-limiting process (Figure 4C) $[35,36]$. In addition, the straight line of Boyd plot which nearly passes through the origin suggests that the external mass transfer kinetics is controlled by intraparticle diffusion.

As shown in Figure 5, the Langmuir and Freundlich isotherm models could simulate the experimental data well. In contrast, the Dubinin-Radushkevich and Temkin models showed high discrepancies between the simulated values and the experimental data, especially at high dye concentrations. The fitting parameters of the simulation best fits are presented in Table 1, indicating that the Langmuir model is the most suitable to explain the adsorption mechanism and distribution of AB25 as a homogeneous monolayer on the PP surface. As AB25 is negatively charged, one could consider that the dye is bound to the PP surface via electrostatic and hydrogen bonding interactions, and this is supported by shifts in the AB25 and PP bands in the FTIR spectra.

To exemplify this interpretation, intermolecular interactions between AB25 and PP in this study were simulated using ab initio calculations using Gaussian basis sets. The structure of AB25 was optimized in Chem3D. The energy minimization was performed using the MMF94 force field. The number of iterations was 500 and the minimum RMS gradient was 0.1. As shown in Figure 6A, it can be seen that AB25 has a relatively planar structure with a slightly out of plane with the secondary amine group twisted with respect to the phenyl ring. Two choices therefore exist for adsorption. The molecule can either 
lay flat allowing hydrogen-bond interactions through all amine, carbonyl, and sulfonate groups, albeit with a less than favorable geometry, or it could position itself with the more accessible $1^{\circ}$ amide and the adjacent carbonyl and sulfonate pointing to the PP surface with a more favorable geometric conformation. The interactions which govern adsorption mechanisms of AB25 were mainly hydrogen bonding interactions involving the $\mathrm{OH}, \mathrm{NH}_{2}$, $\mathrm{C}=\mathrm{O}$, and $\mathrm{COO}^{-}$groups on the PP surface, as schematically illustrated in Figure $6 \mathrm{~B}$.
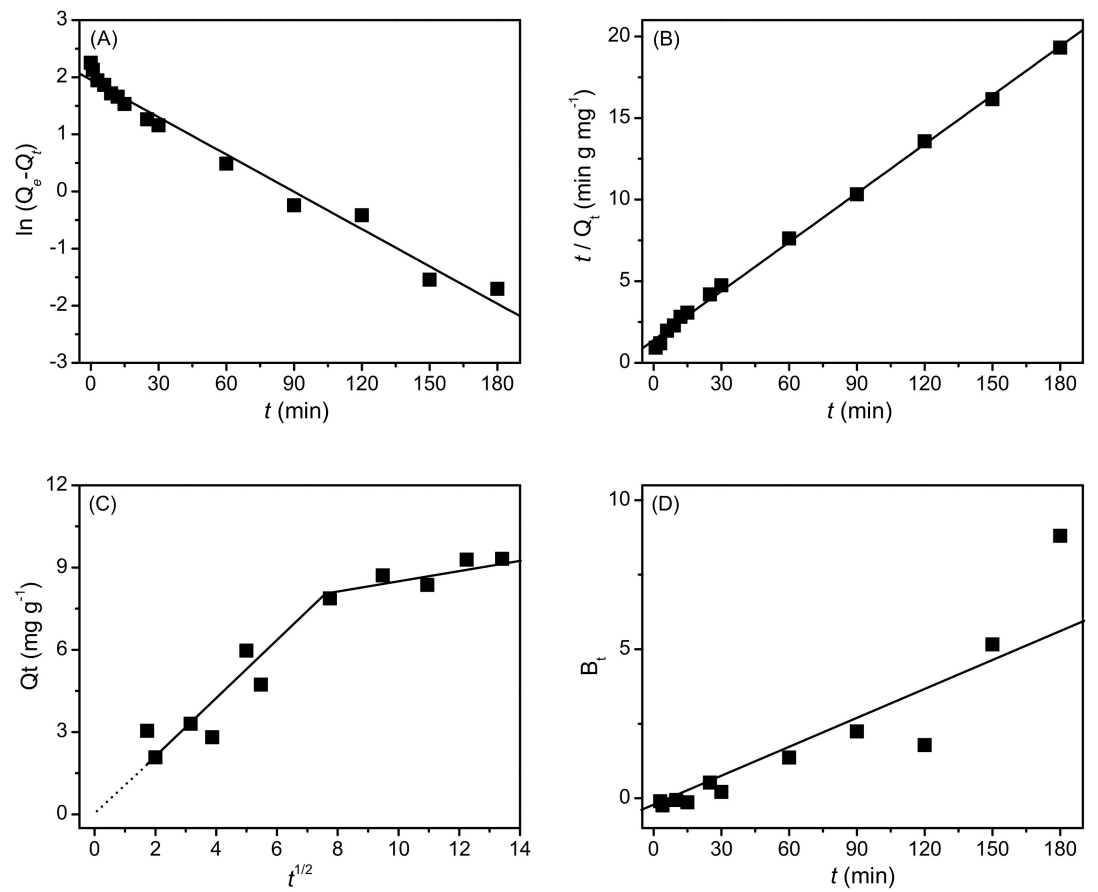

Figure 4. Adsorption kinetic data of AB25 on PP fitted with (A) Lagergren pseudo-first order, (B) pseudo-second order, (C) Weber-Morris intraparticle diffusion, and (D) Boyd diffusion models.
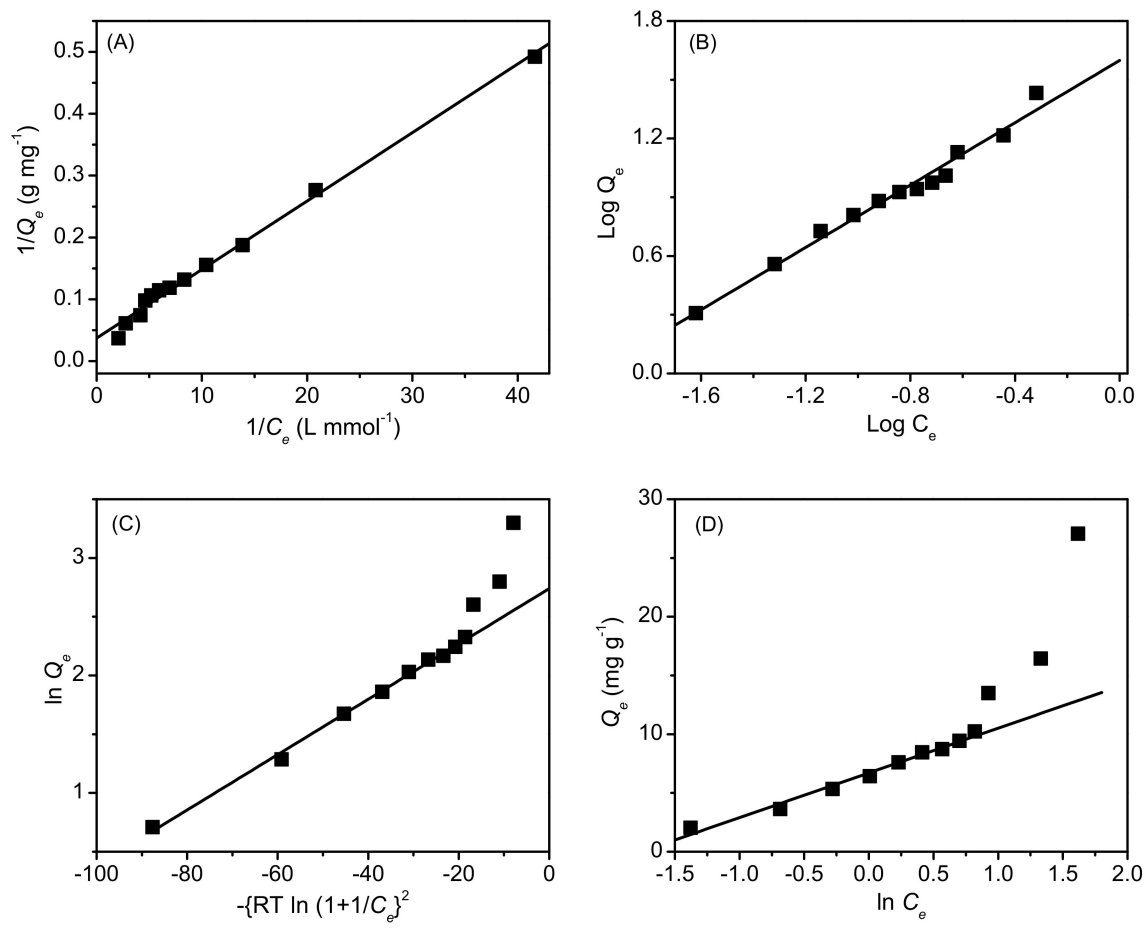

Figure 5. Adsorption isotherm data of AB25 on PP fitted with (A) Langmuir, (B) Freundlich, (C) Dubinin-Radushkevich, and (D) Temkin isotherm models. 
Table 1. The adsorption parameters of AB25 adsorption on PP deduced from the best fits of the empirical Langmuir, Freundlich, Dubinin-Radushkevich, and Temkin isotherm models to the experimental data.

\begin{tabular}{ccc}
\hline Isotherm Model & Parameters & Quantity \\
\hline Langmuir & $\mathrm{Q}_{\mathrm{m}}\left(\mathrm{mg} \mathrm{g}^{-1}\right)$ & 26.9 \\
& $\mathrm{~K}_{\mathrm{L}}\left(\mathrm{dm}^{-3} \mathrm{mmol}^{-1}\right)$ & 3.36 \\
& $\mathrm{R}^{2}$ & 0.993 \\
\hline Freundlich & $\mathrm{K}_{\mathrm{F}}$ & 39.7 \\
& $\mathrm{n}$ & 1.26 \\
& $\mathrm{R}^{2}$ & 0.998 \\
\hline Dubinin-Radushkevich & & \\
& $\mathrm{Q}_{\mathrm{m}}\left(\mathrm{mg} \mathrm{g}^{-1}\right)$ & 20.3 \\
& $\beta$ & 28.6 \\
& $\mathrm{E}\left(\mathrm{kJ} \mathrm{mol}^{-1}\right)$ & 0.132 \\
& $\mathrm{R}^{2}$ & 0.914 \\
\hline Temkin & & \\
& $\mathrm{K}_{\mathrm{T}}\left(\mathrm{dm}^{-3} \mathrm{mmol}^{-1}\right)$ & 2.95 \\
& $\mathrm{~b}_{\mathrm{T}}\left(\mathrm{kJ} \mathrm{mol}^{-1}\right)$ & 0.354 \\
$\mathrm{R}^{2}$ & 0.758 \\
\hline
\end{tabular}

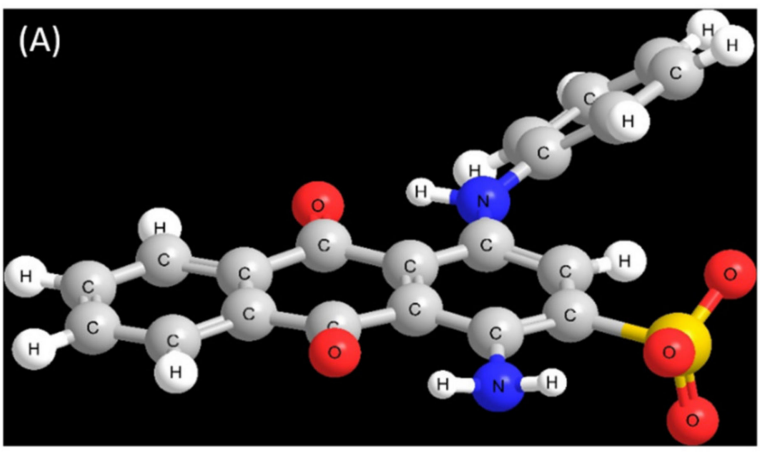

(B)

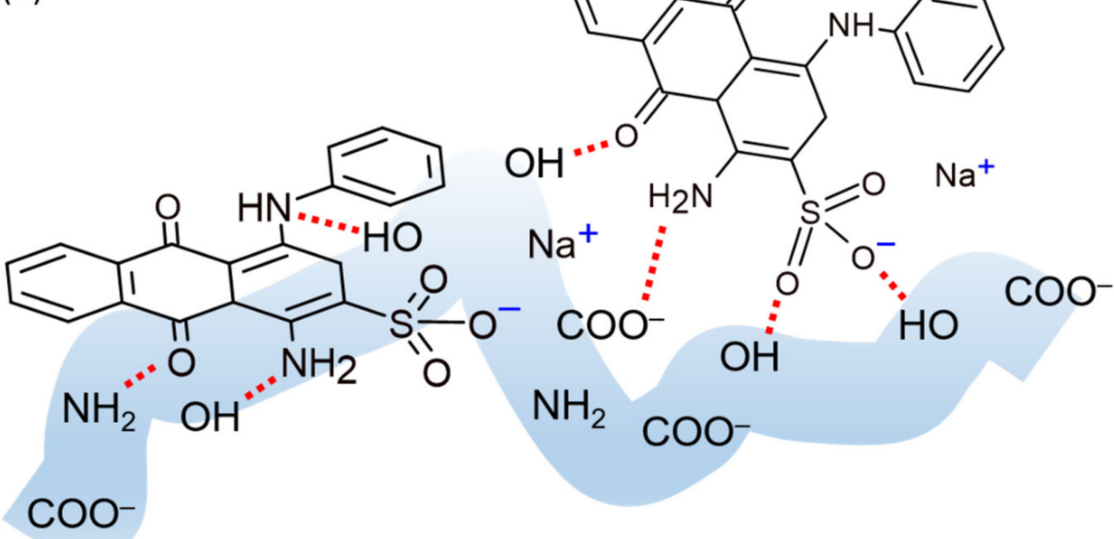

Figure 6. (A) The structure of AB25 optimized using Chem3D (the force field MMF94, 500 iterations, and the minimum RMS gradient 0.1), and (B) possible adsorption geometries of AB25 through hydrogen bonding interactions with the $\mathrm{OH}, \mathrm{NH}_{2}, \mathrm{C}=\mathrm{O}$, and $\mathrm{COO}^{-}$groups on the PP surface. 


\subsection{Comparison of the $Q_{m}$ of $A B 25$}

The $\mathrm{Q}_{\mathrm{m}}$ of $\mathrm{AB} 25$ on PP was estimated to be $26.9 \mathrm{mg} \mathrm{g}^{-1}$ based on the best fit of the Langmuir isotherm mode. The adsorption processes of AB25 reported were in batch mode, and in principle the $Q_{m}$ was calculated with respect to dried mass of the adsorbents. The $\mathrm{Q}_{\mathrm{m}}$ for the removal of AB25 on PP is listed and compared with many different adsorbents reported in the literature. As summarized in Table 2, the $Q_{m}$ for the removal of AB25 on PP was higher than kaolin [37], and it was comparable to those on other reported adsorbents, such as Shorea dasyphylla sawdust [24], pine sawdust [15], cempedak durian peel [25], oak sawdust [15], and rubber leaves powder [29]. However, it was lower compared to rambutan seed (Nephelium lappaceum) [26], walnut sawdust [15], soybean waste [31], Azolla pinnata [31], hazelnut shell [15], banana peel [11], Ficus rasemosa leaves powder [30], durian peel [11], peach seed powder [28], Aspergillus oryzae [38], egg shell modified activated carbon [23], Ceratophylum demersum [14], Potamogeton pusillus [14], activated carbon [22], pectin [21], and chitosan-activated carbon composite [39].

Table 2. Adsorption on PP (current study) and data reported for other adsorbents in the literature.

\begin{tabular}{|c|c|c|c|c|}
\hline Adsorbent & $\mathrm{pH}_{\mathrm{pzc}}$ & pH & $\begin{array}{c}Q_{m} \\
\left(\mathrm{mg} \mathrm{g}^{-1}\right)\end{array}$ & Reference \\
\hline Raw kaolin & 5.70 & 7.3 & 16.5 & [37] \\
\hline Shorea dasyphylla sawdust & 8.25 & 2.0 & 24.4 & [24] \\
\hline Pine sawdust & $2.3-3.8$ & $2.5-4.2$ & 26.2 & [15] \\
\hline Cempedak durian peel & 4.01 & 2 & 26.6 & [25] \\
\hline Pomelo pith & 4.23 & 6.7 & 26.9 & This study \\
\hline Oak sawdust & $2.3-3.8$ & $2.5-4.2$ & 27.9 & [15] \\
\hline Rubber leaves powder & NR * & 2 & 28.1 & [29] \\
\hline Nephelium lappaceum Linn. seed & 6.2 & 2 & 35.6 & [26] \\
\hline Walnut sawdust & $2.3-3.8$ & $2.5-4.2$ & 37.0 & [15] \\
\hline Soybean waste & $\mathrm{NR} *$ & 2 & 38.3 & [31] \\
\hline Azolla pinnata & NR * & 2 & 50.5 & [31] \\
\hline Hazelnut shell & $2.3-3.8$ & $2.5-4.2$ & 60.2 & [15] \\
\hline Banana peel & 6.32 & 6.7 & 70.0 & [11] \\
\hline Ficus rasemosa leaves powder & $\mathrm{NR} *$ & 2 & 83.3 & [30] \\
\hline Durian peel & 6.18 & 6.7 & 89.7 & [11] \\
\hline Peach seed powder & NR * & 2 & 95.2 & {$[28]$} \\
\hline Aspergillus oryzae & $\mathrm{NR} *$ & 2 & 105.3 & [38] \\
\hline Egg shell modified activated carbon & 5.7 & $5.2-5.7$ & 109.8 & [23] \\
\hline Ceratophylum demersum & $\mathrm{NR} *$ & 2 & 129.7 & [14] \\
\hline Potamogeton pusillus & $\mathrm{NR} *$ & 2 & 183.5 & [14] \\
\hline Waste tea activated carbon & 7.2 & $7-11$ & 203.3 & [22] \\
\hline Pectin derived from pomelo peel & 2.63 & 6.7 & 739.0 & {$[21]$} \\
\hline Chitosan-activated carbon composite & NR * & 4 & 909.1 & [39] \\
\hline
\end{tabular}

${ }^{*} \mathrm{NR}=$ not reported.

We note that the literature values of $\mathrm{Q}_{\mathrm{m}}$ were reported at different $\mathrm{pHs}$, depending on the adsorbent. In most of adsorption studies many authors proved that the optimum removal was obtained at $\mathrm{pH} 2-4$ which is below the $\mathrm{pH}$ of point of zero charge $\left(\mathrm{pH}_{\mathrm{pzc}}\right)$ of the adsorbents, making the adsorbents' surface positively charged and favorable for adsorption of negatively charged synthetic dyes. It has been pointed out that the $\mathrm{pH}$ progressively affects the adsorption behavior of AB25 on adsorbents derived from agricultural wastes $[15,39]$. Moreover, based on our experience, changing the medium $\mathrm{pH}$ modifies, not only the ionic state and surface properties of PP adsorbent, but also the ionic state, intermolecular interactions, solubility, and aggregation of AB25. In this study, absorption of AB25 on PP was carried out using an un-buffered aqueous solution of AB25 with a known mass of $\mathrm{PP}$, for which the "ambient" $\mathrm{pH}$ is nearly neutral ( $\mathrm{pH} \sim 6.7)$, and which is above the $\mathrm{pH}$ of point of zero charge $\left(\mathrm{pH}_{\mathrm{pzc}}\right)$ of the adsorbent (4.23). At this $\mathrm{pH}, \mathrm{AB} 25$ is in its anionic form (pKa $\sim 1$ ), whereas the aromatic carboxylic acid (-COOH; pKa 4.8$)$ and primary and secondary amines $\left(-\mathrm{NH}_{2},-\mathrm{NH}-; \mathrm{pKa}<4.6\right)$ of $\mathrm{PP}$ are naturally deprotonated $[40,41]$. This 
offers an interpretation that adsorption of AB25 relies solely on hydrogen bonding interactions with carboxylic acid, amines, hydroxyl $(-\mathrm{OH})$ and other hydrogen bonding active functional groups on the PP surface. Considering that that adsorption of AB25 could be accelerated by electrostatic attraction to the deprotonated form of those functional groups, the difference in $Q_{m}$ values can be partly attributed to differences in $\mathrm{pH}$. In addition, the surface area and pore size of any adsorbent could be modified in solutions with different $\mathrm{pHs}$, which could lead to different adsorption capacities of the adsorbent. However, such a comparison at least provides a broad picture of adsorption characteristics of AB25 onto various adsorbents derived from agricultural wastes.

\subsection{Thermodynamic Parameters of AB25 Adsorption}

As shown in Table 1, the Langmuir isotherm constant, $\mathrm{K}_{\mathrm{L}}$, for the adsorption of AB25 on PP at $25{ }^{\circ} \mathrm{C}$, is $3.36 \mathrm{dm}^{3} \mathrm{mmol}^{-1}$. Similar experiments were performed at different temperatures in the range $293-313 \mathrm{~K}$. The estimated $\mathrm{K}_{\mathrm{L}}$ at each temperature was converted to dimensionless equilibrium constant, $\mathrm{K}_{\mathrm{e}}^{0}$, and the Gibbs free energy $\left(\Delta \mathrm{G}_{\mathrm{ads}}\right)$ was calculated based on Van't Hoff equation, $\Delta \mathrm{G}_{\mathrm{ads}}=-\mathrm{RT} \ln \mathrm{K}_{\mathrm{e}}^{0}$. It was found that $\mathrm{K}_{\mathrm{e}}^{0}$ increased and, hence, $\Delta \mathrm{G}_{\text {ads }}$ decreased, as temperature increased (see Table 3$)$. This result suggests that adsorption of AB25 onto PP is spontaneous, and that the adsorption is energetically more favorable at higher temperatures. Based on the linear plot of $\Delta \mathrm{G}_{\mathrm{ads}}$ against temperature (see Supplementary Information Figure S2), the enthalpy $(\Delta \mathrm{H})$ and entropy $(\Delta \mathrm{S})$ were then estimated to be $10.4 \mathrm{~kJ} \mathrm{~mol}^{-1}$ and $52 \mathrm{~J} \mathrm{~mol}^{-1} \mathrm{~K}^{-1}$, respectively, suggesting that the adsorption process is endothermic. It is interesting to note that $\Delta \mathrm{S}$ of $\mathrm{AB} 25$ adsorption on $\mathrm{PP}$ is higher compared to that on pectin $\left(47 \mathrm{~J} \mathrm{~mol}^{-1} \mathrm{~K}^{-1}\right)$, but it is much smaller compared with those on other agricultural wastes, such as BP and DP $\left(8.02\right.$ and $0.82 \mathrm{~kJ} \mathrm{~mol}^{-1} \mathrm{~K}^{-1}$, respectively). These results suggest that the PP surface is slightly less energetically stable than the pectin surface, but more stable than the surfaces of other agricultural wastes. In other words, upon AB25 adsorption, it was easier for the PP surface to become irregular as compared with pectin $[42,43]$.

Table 3. The thermodynamic parameters of AB25 adsorption on PP.

\begin{tabular}{|c|c|c|c|c|c|c|}
\hline \multirow{2}{*}{ Adsorbent } & \multirow{2}{*}{$\mathbf{T}(\mathbf{K})$} & $\mathrm{K}_{\mathrm{L}}$ & $\mathbf{K}_{\mathbf{e}}^{0}$ & $\Delta \mathrm{G}_{\mathrm{ads}}$ & $\Delta \mathbf{H}$ & $\Delta \mathrm{S}$ \\
\hline & & $\left(\mathrm{kJ} \mathrm{mol}^{-1}\right)$ & & $\left(\mathrm{kJ} \mathrm{mol}^{-1}\right)$ & $\left(\mathrm{kJ} \mathrm{mol}^{-1}\right)$ & $\left(\mathrm{J} \mathrm{mol}^{-1} \mathrm{~K}^{-1}\right)$ \\
\hline \multirow{5}{*}{ PP } & 293 & 3.23 & 7420 & -4.77 & \multirow{5}{*}{10.4} & \multirow{5}{*}{52} \\
\hline & 298 & 3.36 & 7728 & -4.95 & & \\
\hline & 303 & 3.95 & 9078 & -5.43 & & \\
\hline & 308 & 3.96 & 9106 & -5.53 & & \\
\hline & 313 & 4.22 & 9683 & -5.77 & & \\
\hline
\end{tabular}

\section{Materials and Methods}

\subsection{Chemicals}

AB25 sodium salt $\left(\mathrm{C}_{20} \mathrm{H}_{13} \mathrm{~N}_{2} \mathrm{O}_{5} \mathrm{SNa}\right)$ with a molecular weight of $416.38 \mathrm{~g} \mathrm{~mol}^{-1}$ and a molar decadic extinction coefficient of $1.05 \times 10^{4} \mathrm{dm}^{-3} \mathrm{~mol}^{-1} \mathrm{~cm}^{-1}$ at $600 \mathrm{~nm}$, was purchased from Sigma-Aldrich Co. (St. Louis, MO, USA), and used as received. Aqueous solutions containing different concentrations of AB25 were prepared and the dye concentration was estimated based on the UV-visible absorption spectrum, measured on a Shimadzu UV-1900 (Shimadzu, Tokyo, Japan), in the range of 200-800 nm, using $1 \mathrm{~cm}$ path length cuvette.

PP was obtained from pomelo fruit by separating it from the fruit meat and flavedo. It was then chopped into small pieces and dried at $40{ }^{\circ} \mathrm{C}$ in an oven. After drying, the PP was ground into a course powder using a blender, sieved through $212 \mu \mathrm{m}$ mesh, and used as an adsorbent. 


\subsection{Characterizations}

The available functional groups on PP and intermolecular interactions of AB25 on the PP surface were determined based on its vibrational spectrum recorded on an FTIR spectrometer (IR Prestige-21, Shimadzu, Tokyo, Japan). Its surface morphology was characterized by scanning electron microscopy (SEM) using a JEOL JSM-7600F (JEOL, Tokyo, Japan). The surface characteristics, including Brunauer-Emmett-Teller (BET) surface area and Barrett-Joyner-Halenda (BJH) pore size distribution, were measured on a surface analyzer (ASAP 2460, Micromeritics, Norcross, GA, USA).

\subsection{Adsorption of $A B 25$ of $P P$}

Mixture of AB25 stock solutions with a known mass of PP were gently shaken using an orbital shaker. The amount of adsorption was evaluated at different contact times. Typically, $20 \mathrm{~cm}^{3}$ of AB25 solution with an initial concentration, $C_{0}=1.20 \times 10^{-4} \mathrm{~mol} \mathrm{dm}^{-3}$, was mixed with $25 \mathrm{mg}$ of PP in conical flasks. The colloidal mixtures were shaken at room temperature for different contact times, $t$, from 0 to $240 \mathrm{~min}$, followed by centrifugation. The solutions were separated, and their UV-visible absorption spectra were measured. In other experiments, the initial concentration of AB25 was varied from $0.48 \times 10^{-4}-9.60 \times 10^{-4} \mathrm{~mol} \mathrm{dm}{ }^{-3}$. A total of $20 \mathrm{~cm}^{3}$ of these solutions was mixed with $25 \mathrm{mg}$ PP and the adsorption was terminated after $180 \mathrm{~min}$ of contact time. The effect of adsorbent dosage was determined from the adsorption from $20 \mathrm{~cm}^{3}$ AB25 solution $\left(1.20 \times 10^{-4} \mathrm{~mol} \mathrm{dm}^{-3}\right)$ mixed with $25-200 \mathrm{mg}$ PP. The thermodynamics of the adsorption process were investigated from a mixture of $20 \mathrm{~mL} \mathrm{AB25}$ solution $\left(1.20 \times 10^{-4} \mathrm{~mol} \mathrm{dm}^{-3}\right)$ with $25 \mathrm{mg} \mathrm{PP}$, in the temperature range of $20-40{ }^{\circ} \mathrm{C}$. All the adsorption experiments were carried out in duplicate, and all the collected data were combined and analyzed.

In every case, the residual concentration $\left(C_{t}\right)$ was determined based on the absorption spectrum of the remaining solution. The adsorptive efficiency $(\eta)$ was calculated from, $\eta(\%)=100\left(C_{0}-C_{t}\right) / C_{0}$, and the adsorption removal capacity $\left(\mathrm{Q}_{t}\right)$ was estimated using $Q_{t}=\left(C_{0}-C_{t}\right) V / M$; where $M$ is the mass of $P P$, and $V$ is the volume of $A B 25$ solution, respectively.

The adsorption kinetics of AB25 on PP was carefully monitored at early contact times from 0 to $180 \mathrm{~min}$. The time-dependent $Q_{t}$ data were analyzed using Lagergren pseudofirst order and pseudo-second order reaction laws with $\mathrm{k}_{1}$ and $\mathrm{k}_{2}$ being the respective rate constants [44];

$$
\begin{gathered}
\ln \left(Q_{e}-Q_{t}\right)=\ln Q_{e}-k_{1} t \\
t / Q_{t}=1 / k_{2} Q_{e}^{2}+t / Q_{e}
\end{gathered}
$$

To determine the rate-limiting step of in the adsorption of $A B 25$, the same $Q_{t}$ data were also simulated using homogenous surface diffusion models, including the Boyd diffusion and the Weber-Morris pore-volume intraparticle models [45-48];

$$
\begin{gathered}
\mathrm{B}_{\mathrm{t}}=-0.4977-\ln \left(1-\mathrm{Q}_{\mathrm{t}} / \mathrm{Q}_{\mathrm{e}}\right) \\
\mathrm{Q}_{\mathrm{t}}=\mathrm{k}_{\mathrm{i}} \mathrm{t}^{1 / 2}+\mathrm{C}
\end{gathered}
$$

where $B_{t}$ is Boyd constant of the AB25 adsorption, $k_{i}$ is the rate constant of intraparticle diffusion, and $C$ is the thickness of the boundary layer.

The adsorption isotherm of AB25 on PP was analyzed using Langmuir, Freundlich, Dubinin-Radushkevich, and Temkin isotherm models [49];

$$
\begin{gathered}
1 / \mathrm{Q}_{\mathrm{e}}=1 / \mathrm{Q}_{\mathrm{m}} \mathrm{K}_{\mathrm{L}} \times 1 / \mathrm{C}_{\mathrm{e}}+1 / \mathrm{Q}_{\mathrm{m}} \\
\log \mathrm{Q}_{\mathrm{e}}=\frac{1}{\mathrm{n}} \log \mathrm{C}_{\mathrm{e}}+\log \mathrm{K}_{\mathrm{F}} \\
\ln \mathrm{Q}_{\mathrm{e}}=\ln \mathrm{Q}_{\mathrm{m}}-\beta\left\{\mathrm{RT} \ln \left(1+\frac{1}{\mathrm{C}_{\mathrm{e}}}\right)\right\}^{2}
\end{gathered}
$$




$$
\mathrm{Q}_{\mathrm{e}}=\frac{\mathrm{RT}}{\mathrm{b}_{\mathrm{T}}}\left(\ln \mathrm{K}_{\mathrm{T}}+\ln \mathrm{C}_{\mathrm{e}}\right)
$$

where $\mathrm{R}$ is the gas constant, and $\mathrm{T}$ is absolute temperature. The physical quantities governing the adsorption process, including the maximum adsorption capacity $\left(\mathrm{Q}_{\mathrm{m}}\right)$, the Langmuir, Freundlich, and Temkin isotherm constants $\left(\mathrm{K}_{\mathrm{L}}, \mathrm{K}_{\mathrm{F}}\right.$, and $\left.\mathrm{K}_{\mathrm{T}}\right)$, Freundlich and Temkin exponent factor $\left(n\right.$ and $b_{T}$ ), the Dubinin-Radushkevich mean free energy change $(\beta)$, were determined based on the best fits of the isotherm models on the adsorption isotherm data. The mean adsorption energy, $\mathrm{E}\left(\mathrm{kJ} \mathrm{mol}^{-1}\right)$, was calculated using $\mathrm{E}=(2 \beta)^{-1 / 2}$.

The thermodynamics of AB25 adsorption on PP was evaluated by calculating dimensionless equilibrium constant, $\mathrm{K}_{\mathrm{e}}^{0}$, [50];

$$
\mathrm{K}_{\mathrm{e}}^{0}=\mathrm{K}_{\mathrm{L}} \times[\mathrm{AB} 25] / \gamma
$$

where $[\mathrm{AB} 25]$ is the concentration $\left(1.20 \times 10^{-4} \mathrm{~mol} \mathrm{dm}^{-3}\right)$, and thus $\gamma$, which is the activity coefficient of solution, was approximated to be unitary

\section{Conclusions}

In this study, the adsorptive removal and dynamic interactions of AB25, a negatively charged dye, on pomelo pith (PP) was investigated across different parameters. It was found that the adsorption kinetics was pseudo-second order with a rate constant of $0.007 \mathrm{~g} \mathrm{mg}^{-1} \mathrm{~min}^{-1}$. An adsorption-desorption equilibrium was reached at $120 \mathrm{~min}$, suggesting that there is low affinity of PP towards the acidic dye. The rate-limiting step of the adsorption process was intraparticle diffusion of external mass transfer. The vibrational spectroscopic analysis suggested that AB25 is bound to the PP surface via electrostatic and hydrogen bonding interactions. The adsorption mechanism could be explained by the Langmuir isotherm model, demonstrating that the AB25 adsorption took place and distributed homogeneously as a monolayer on the PP surface, with a maximum adsorption capacity of $26.9 \mathrm{mg} \mathrm{g}^{-1}$. This is comparable to many values reported for other adsorbents derived from agricultural wastes. The low adsorption capacity of AB25 can be explained by proposing that there is a low affinity of the negatively charged PP surface towards the anionic dye. The results could also be an indication that the adsorption of dyes strongly depends on their interactions, via electrostatic and hydrogen bonding, to functional groups rather than the BET surface area of the adsorption surface. The derived thermodynamic parameters suggested that AB25 was spontaneously adsorbed on the PP surface, and that the adsorption was endothermic and energetically more favorable at higher temperatures. The entropy change of AB25 adsorption on PP is much smaller than previously reported values on other agricultural waste adsorbates, suggesting that the PP surface is energetically more stable, compared with that of other agricultural wastes. These results all show that PP has great potential for use in extracting similar toxins from wastewaters, and that scale up to industrial levels would be appropriate to test this. This is motivated by the low cost of PP and its efficiency of action.

Supplementary Materials: The following supporting information can be downloaded online, Figure S1: The adsorption efficiency $(\eta)$ of $20 \mathrm{~cm}^{3}$ AB25 $\left(1.20 \times 10^{-4} \mathrm{~mol} \mathrm{dm}^{-3}\right)$ in the presence of different dosages of PP from $25 \mathrm{mg}$ to $300 \mathrm{mg}$, Figure S2: Plot of $\Delta \mathrm{G}_{\text {ads }}$ against temperature based on adsorption of $20 \mathrm{~mL} \mathrm{AB25}\left(1.20 \times 10^{-4} \mathrm{~mol} \mathrm{dm}^{-3}\right)$ in the presence of $25 \mathrm{mg}$ of PP.

Author Contributions: Conceptualization, A.U.; methodology, A.U. and E.W.E.S.S.; validation, A.U., J.H. and M.N.; investigation, E.W.E.S.S., N.A.H.N., N.N.M.S. and S.B.V.; writing-original draft preparation, A.U. and E.W.E.S.S.; writing-review and editing, A.U. and J.H.; supervision, A.U. and M.N. All authors have read and agreed to the published version of the manuscript.

Funding: This research received no external funding.

Institutional Review Board Statement: Not applicable.

Informed Consent Statement: Not applicable. 


\section{Data Availability Statement: Not applicable.}

Acknowledgments: Jonathan Hobley is grateful to National Cheng Kung University's NCKU90 Distinguished Visiting Scholar Program for hosting his research.

Conflicts of Interest: The authors declare no conflict of interest.

Sample Availability: Samples of the compounds are not available from the authors.

\section{References}

1. Ardila-Leal, L.D.; Poutou-Piñales, R.A.; Pedroza-Rodríguez, A.M.; Quevedo-Hidalgo, B.E. A brief history of colour, the environmental impact of synthetic dyes and removal by using laccases. Molecules 2021, 26, 3813. [CrossRef] [PubMed]

2. Palani, G.; Arputhalatha, A.; Kannan, K.; Lakkaboyana, S.K.; Hanafiah, M.M.; Kumar, V.; Marella, R.K. Current trends in the application of nanomaterials for the removal of pollutants from industrial wastewater treatment-A review. Molecules 2021, 26, 2799. [CrossRef] [PubMed]

3. Zazouli, M.A.; Kalankesh, L.R. Removal of precursors and disinfection by-products (DBPs) by membrane fltration from water: A review. J. Environ. Health Sci. Eng. 2017, 15, 25. [CrossRef] [PubMed]

4. Gadekar, M.R.; Ahammed, M.M. Use of water treatment residuals for colour removal from real textile dye wastewater. Appl. Water Sci. 2020, 10, 160. [CrossRef]

5. Wang, J.L.; Xu, L.J. Advanced oxidation processes for wastewater treatment: Formation of hydroxyl radical and application. Crit. Rev. Environ. Sci. Technol. 2012, 42, 251-325. [CrossRef]

6. Suhaimi, N.A.A.; Shahri, N.N.M.; Samat, J.H.; Kusrini, E.; Lim, J.-W.; Hobley, J.; Usman, A. Domination of methylene blue over rhodamine $\mathrm{B}$ during simultaneous photocatalytic degradation by $\mathrm{TiO}_{2}$ nanoparticles in an aqueous binary solution under UV irradiation. React. Kinet. Mech. Cat. 2022, 135, 511-527. [CrossRef]

7. Bagheri, F.; Chaibakhsh, N. Efficient visible-light photocatalytic ozonation for dye degradation using $\mathrm{Fe}_{2} \mathrm{O}_{3} / \mathrm{MoS}_{2}$ nanocomposite. Sep. Sci. Technol. 2021, 56, 3022-3032. [CrossRef]

8. Hynes, N.R.J.; Kumar, J.S.; Kamyab, H.; Sujana, J.A.J.; Al-Khashman, O.A.; Kuslu, Y.; Ene, A.; Kumar, B.S. Modern enabling techniques and adsorbents based dye removal with sustainability concerns in textile industrial sector-A comprehensive review. J. Clean. Prod. 2020, 272, 122636. [CrossRef]

9. Zamri, N.I.I.; Zulmajdi, S.L.N.; Daud, N.Z.A.; Mahadi, A.H.; Kusrini, E.; Usman, A. Insight into the adsorption kinetics, mechanism, and thermodynamics of methylene blue from aqueous solution onto pectin-alginate-titania composite microparticles. SN Appl. Sci. 2021, 3, 222. [CrossRef]

10. Asbollah, M.A.; Mahadi, A.H.; Kusrini, E.; Usman, A. Synergistic effect in concurrent removal of toxic methylene blue and acid red-1 dyes from aqueous solution by durian rind: Kinetics, isotherm, thermodynamics, and mechanism. Int. J. Phytoremediat. 2021, 23, 1432-1443. [CrossRef]

11. Samat, J.H.; Shahri, N.N.M.; Abdullah, M.A.; Suhaimi, N.A.A.; Padmosoedarso, K.M.; Kusrini, E.; Mahadi, A.H.; Hobley, J.; Usman, A. Adsorption of Acid Blue 25 on agricultural wastes: Efficiency, kinetics, mechanism, and regeneration. Air Soil Water Res. 2021, 14, 1-12. [CrossRef]

12. Wawrzkiewicz, M.; Hubicki, Z. Anion Exchange Resins as Efective Sorbents for Removal of Acid, Reactive, and Direct Dyes from Textile Wastewaters. In Ion Exchange-Studies and Applications; Kilislioglu, A., Ed.; IntechOpen: Rijeka, Croatia, 2015.

13. Zhang, M.-H.; Dong, H.; Zhao, L.; Wang, D.-X.; Meng, D. A review on Fenton process for organic wastewater treatment based onoptimization perspective. Sci. Total Environ. 2019, 670, 110-121. [CrossRef]

14. Kousha, M.; Daneshvar, E.; Esmaeili, A.R.; Zilouei, H.; Karimi, K. Biosorption of toxic acidic dye-acid blue 25 by aquatic plants. Desalin. Water Treat. 2014, 52, 6756-6769. [CrossRef]

15. Ferrero, F. Dye removal by low cost adsorbents: Hazelnut shells in comparison with wood sawdust. J. Hazard. Mater. 2007, 142, 144-152. [CrossRef]

16. Zaidi, N.A.H.M.; Lim, L.B.L.; Priyantha, N.; Usman, A. Artocarpus odoratissimus leaves as an eco-friendly adsorbent for the removal of toxic rhodamine $B$ dye in aqueous solution: Equilibrium isotherm, kinetics, thermodynamics and regeneration studies. Arab. J. Sci. Eng. 2018, 43, 6011-6020. [CrossRef]

17. Kusrini, E.; Usman, A.; Sani, F.A.; Wilson, L.D.; Abdullah, M.A.A. Simultaneous adsorption of lanthanum and yttrium from aqueous solution by durian rind biosorbent. Environ. Monit. Assess. 2019, 191, 488. [CrossRef]

18. Dinh, V.-P.; Huynh, T.D.; Le, H.M.; Nguyen, V.-D.; Dao, V.-A.; Hung, N.Q.; Tuyen, L.A.; Lee, S.; Yi, J.; Nguyen, T.D.; et al. Insight into the adsorption mechanisms of methylene blue and chromium(III) from aqueous solution onto pomelo fruit peel. RSC Adv. 2019, 9, 25847-25860. [CrossRef]

19. Lewis, D.M. The Coloration of Wool. In Advances in Wool Technology; Johnson, N.A.G., Russell, I.M., Eds.; Woodhead Publishing Limited: Cambridge, UK, 2009; pp. 183-213. 
20. El-Hamshary, H.; Elsherbiny, A.S.; El-Newehy, M.H.; El-Hefnawy, M.E. Polyaspartate-Ionene/Na ${ }^{+}$-Montmorillonite nanocomposites as novel adsorbent for anionic dye; effect of ionene structure. Polymers 2020, 12, 2843. [CrossRef]

21. Shahrin, E.W.E.S.; Narudin, N.A.H.; Padmosoedarso, K.M.; Kusrini, E.; Mahadi, A.H.; Shahri, N.N.M.; Usman, A. Pectin derived from pomelo pith as a superior adsorbent to remove toxic Acid Blue 25 from aqueous solution. Carbohydr. Polym. Technol. Appl. 2021, 2, 100116. [CrossRef]

22. Auta, M.; Hameed, B.H. Preparation of waste tea activated carbon using potassium acetate as an activating agent for adsorption of Acid Blue 25 dye. Chem. Eng. J. 2011, 171, 502-509. [CrossRef]

23. Tovar-Gómez, R.; Rivera-Ramírez, D.A.; Hernández-Montoya, V.; Bonilla-Petriciolet, A.; Durán-Valle, C.J.; Montes-Morán, M.A Synergic adsorption in the simultaneous removal of Acid Blue 25 and heavy metals from water using a $\mathrm{Ca}\left(\mathrm{PO}_{3}\right)_{2}$-modified carbon. J. Hazard. Mater. 2012, 199-200, 290-300. [CrossRef]

24. Hanafiah, M.A.K.M.; Ngah, W.S.W.; Zolkafly, S.H.; Teong, L.C.; Majid, Z.A.A. Acid blue 25 adsorption on base treated Shorea dasyphylla sawdust: Kinetic, isotherm, thermodynamic and spectroscopic analysis. J. Environ. Sci. 2012, 24, 261-268. [CrossRef]

25. Dahri, M.K.; Lim, L.B.L.; Priyantha, N.; Chan, C.M. Removal of Acid Blue 25 using cempedak durian peel from aqueous medium: Isotherm, kinetics and thermodynamics studies. Int. Food Res. J. 2016, 23, 1154-1163.

26. Lakkaboyana, S.K.; Khantong, S.; Kabir, M.A.; Ali, Y.; Yaacob, W.Z.W. Removal of Acid Blue 25 dye from wastewater using rambutan (Nephelium lappaceum Linn.) seed as an efficient natural biosorbent. Indian J. Adv. Chem. Sci. 2018, 6, 111-117.

27. Kousha, M.; Tavakoli, S.; Daneshvar, E.; Vazirzadeh, A.; Bhatnagar, A. Central composite design optimization of Acid Blue 25 dye biosorption using shrimp shell biomass. J. Mol. Liq. 2015, 207, 266-273. [CrossRef]

28. Kul, A.R.; Aldemir, A.; Elik, H. Adsorption of Acid Blue 25 on peach seed powder: Isotherm, kinetic and thermodynamic studies Environ. Res. Technol. 2019, 2, 233-242. [CrossRef]

29. Khalid, K.; Ngah, W.S.W.; Hanafiah, M.A.K.M.; Malek, N.S.A.; Khazaai, S.N.M. Acid Blue 25 adsorption onto phosphoric acid treated rubber leaf powder. Am. J. Environ. Eng. 2015, 5, 19-25.

30. Jain, S.N.; Gogate, P.R. NaOH-treated dead leaves of Ficus racemosa as an efficient biosorbent for Acid Blue 25 removal. Int. J. Environ. Sci. Technol. 2017, 14, 531-542. [CrossRef]

31. Kooh, M.R.R.; Dahri, M.K.; Lim, L.B.L.; Lim, L.H. Batch adsorption studies on the removal of acid blue 25 from aqueous solution using Azolla pinnata and soya bean waste. Arab. J. Sci. Eng. 2016, 41, 2453-2464. [CrossRef]

32. Jawad, A.H.; Rashid, R.A.; Ishak, M.A.M.; Ismail, K. Adsorptive removal of methylene blue by chemically treated cellulosic waste banana (Musa sapientum) peels. J. Taibah Univ. Sci. 2018, 12, 809-819. [CrossRef]

33. Zaidi, N.A.H.M.; Lim, L.B.L.; Usman, A. Enhancing adsorption of malachite green dye using base-modified Artocarpus odoratissimus leaves as adsorbents. Environ. Technol. Innov. 2019, 13, 211-223. [CrossRef]

34. Pirali-Hamedani, M.; Mehdipour-Ataei, S. Effect of sulfonation degree on molecular weight, thermal stability, and proton conductivity of poly(arylene ether sulfone)s membrane. Des. Monomers Polym. 2017, 20, 54-65. [CrossRef] [PubMed]

35. Dotto, G.L.; Pinto, L.A.A. Analysis of mass transfer kinetics in the biosorption of synthetic dyes onto Spirulina platensis nanoparticles. Biochem. Eng. J. 2012, 68, 85-90. [CrossRef]

36. Dotto, G.L.; McKay, G. Current scenario and challenges in adsorption for water treatment. J. Environ. Chem. Eng. 2020, 8,103988 [CrossRef]

37. Asbollah, M.A.; Sahid, M.S.M.; Padmosoedarso, K.M.; Mahadi, A.H.; Kusrini, E.; Hobley, J.; Usman, A. Individual and competitive adsorption of negatively charged Acid Blue 25 and Acid Red 1 onto Raw Indonesian kaolin clay. Arab. J. Sci. Eng. 2022, 1-14. [CrossRef]

38. Yang, Y.; Jin, D.; Wang, G.; Wang, S.; Jia, X.; Zhao, Y. Competitive biosorption of Acid Blue 25 and Acid Red 337 onto unmodified and CDAB-modified biomass of Aspergillus oryzae. Bioresour. Technol. 2011, 102, 7429-7436. [CrossRef]

39. Saheed, I.O.; Oh, W.-D.; Suah, F.B.M. Enhanced adsorption of acid Blue-25 dye onto chitosan/porous carbon composite modified in 1-allyl-3-methyl imidazolium bromide ionic liquid. Int. J. Biol. Macromol. 2021, 183, 1026-1033. [CrossRef]

40. Pathak, P.D.; Mandavgane, S.A.; Kulkarni, B.D. Fruit peel waste: Characterization and its potential uses. Curr. Sci. 2017, 113, 444-454. [CrossRef]

41. Zeng, Y.; Chen, X.; Zhao, D.; Li, H.; Zhang, Y.; Xiao, X. Estimation of pKa values for carboxylic acids, alcohols, phenols and amines using changes in the relative Gibbs free energy. Fluid Phase Equilibria 2012, 313, 148-155. [CrossRef]

42. Goswami, S.; Ghosh, U.C. Studies on adsorption behaviour of $\mathrm{Cr}(\mathrm{VI})$ onto synthetic hydrous stannic oxide. Water SA 2005, 31, 597-602.

43. Jiménez-Ángeles, F.; Khoshnood, A.; Firoozabadi, A. Molecular dynamics simulation of the adsorption and aggregation of ionic surfactants at liquid-solid interfaces. J. Phys. Chem. C 2017, 121, 25908-25920. [CrossRef]

44. Revellame, E.D.; Fortela, D.L.; Sharp, W.; Hernandez, R.; Zappi, M.E. Adsorption kinetic modeling using pseudo-first order and pseudo-second order rate laws: A review. Clean. Eng. Technol. 2020, 1, 100032. [CrossRef]

45. Ho, Y.S.; Ng, J.C.Y.; McKay, G. Kinetics of pollutant sorption by biosorbents: Review. Sep. Purif. Methods 2000, $29,189-232$. [CrossRef]

46. Viegas, R.M.C.; Campinas, M.; Costa, H.; Rosa, M.J. How do the HSDM and Boyd's model compare for estimating intraparticle diffusion coefficients in adsorption processes. Adsorption 2014, 20, 737-746.

47. Să̆, Y.; Aktay, Y. Mass transfer and equilibrium studies for the sorption of chromium ions onto chitin. Process Biochem. 2000, 36, 157-173. [CrossRef] 
48. Ermolenko, A.; Shevelev, A.; Vikulova, M.; Blagova, T.; Altukhov, S.; Gorokhovsky, A.; Godymchuk, A.; Burmistrov, I.; Offor, P.O Wastewater treatment from lead and strontium by potassium polytitanates: Kinetic analysis and adsorption mechanism. Processes 2020, 8, 217. [CrossRef]

49. Ghaffari, H.R.; Pasalari, H.; Tajvar, A.H.; Dindarloo, K.; Goudarzi, B.; Alipour, V.; Ghanbarneajd, A. Linear and nonlinear two-parameter adsorption isotherm modeling: A case-study. Int. J. Eng. Sci. 2017, 6, 1-11.

50. Lima, E.C.; Hosseini-Bandegharaei, A.; Moreno-Piraján, J.C.; Anastopoulos, I. A critical review of the estimation of the thermodynamic parameters on adsorption equilibria. Wrong use of equilibrium constant in the Van't Hoof equation for calculation of thermodynamic parameters of adsorption. J. Mol. Liq. 2019, 273, 425-434. [CrossRef] 